\title{
Participação social na Conferência Municipal de Olinda: mito ou realidade?
}

\author{
Social Participation in the Municipal Conference of Olinda: Mith or Reality?
}

\author{
Flávia Lopes Pacheco ${ }^{1}$ \\ Ana Beatriz Nunes da Silva ${ }^{2}$ \\ Alessandra Cabral Nogueira ${ }^{3}$
}

\section{Resumo}

As manifestações realizadas no Brasil, a partir do final da década de 80, começaram a influenciar o novo discurso político que passou a simbolizar o interesse em promover um encontro mais amplo entre o Estado e a sociedade. 0 governo Lula trouxe novas esperanças para a sociedade, em que a Administração Pública passa a ser desenvolvida a partir de um modelo de gestão societal, e não mais gerencial. Assim, neste trabalho buscamos analisar se as práticas desenvolvidas pelo Ministério da Cultura Brasileiro, através da I Conferência Municipal Cultural de Olinda, realizada em 2005, podem caracterizar uma maior participação social na gestão da política de cultura nacional. 0 nosso intuito aqui foi o de compreender se essa prática está sendo desenvolvida a partir da participação tanto dos entes federados como da sociedade na elaboração de uma política pública nacional. No entanto, o que pudemos concluir é que o atual governo, apesar de possuir um discurso diferente dos demais, de parecer não destacar o neoliberalismo econômico e buscar efetivar a ação da sociedade, ainda está longe de promover uma plena participação social. Há que se analisar o processo democrático brasileiro de modo cauteloso, pois não é fácil dividir poderes, como foi percebido nesse caso.

Palavras-chave: Participação social, Estado, Sociedade

\begin{abstract}
The manifestations occurred in Brazil, at the end of the 80's, symbolized the interest in promoting a new meeting between State and society. The government of Lula brought new hopes for society and developed a new model of societal management in Public Administration. The objective of this paper is to analyze whether these practices developed by the Brazilian Ministry of Culture (through the I Cultural Municipal Conference of Olinda, occurred in 2005), can characterize a bigger social participation in the management of the politics of national culture. We tried to understand whether these practices are being developed from the participation of both the federated beings and society for the development of a national public politics. We concluded that, although the current government possesses a different speech, not seeming to focus on economic neo-liberalism and searching to accomplish society action, is still far from promoting a full social participation. It's necessary to analyze the Brazilian democratic process carefully, since it is not easy to share power.
\end{abstract}

Keywords: Social participation, State, Society

\footnotetext{
1 Doutoranda em Administração. Pesquisadora do Observatório da Realidade Organizacional / PROPAD / UFPE - Av. Prof. Moraes Rêgo, 1235 - Cidade Universitária, Recife - Pernambuco - Brasil - Cep: 50670-901 - E-mail: flavialpacheco@yahoo.com.br

2 Mestra em Administração. Pesquisadora do Observatório da Realidade Organizacional / PROPAD / UFPE - Av. Prof. Moraes Rêgo, 1235 - Cidade Universitária, Recife - Pernambuco - Brasil - Cep: 50670-901 - E-mail: anabns@hotmail.com

3 Mestra em Administração. Pesquisadora do Observatório da Realidade Organizacional / PROPAD / UFPE - Av. Prof. Moraes Rêgo, 1235 - Cidade Universitária, Recife - Pernambuco - Brasil - Cep: 50670-901 - E-mail: alessandranog@ hotmail.com

Artigo recebido em outubro de 2006 e aceito para publicação em dezembro de 2006
} 


\section{Introdução}

Os movimentos sociais que surgiram a partir da década de 1970, estimulados por uma clara oposição ao Estado autoritário existente, foram de grande relevância para uma maior atuação da sociedade no Brasil. As manifestações realizadas naquele período começaram a influenciar o novo discurso político brasileiro que, a partir do final da década de 1980, passou a simbolizar o interesse em promover um encontro mais amplo entre o Estado e a sociedade. Temos assim, a Constituição Federal de 1988 como um marco formal desse processo. A partir desse momento, parte-se do pressuposto de que o desenvolvimento de um país deve estar atrelado à sua capacidade cultural de formular um "projeto nacional" que possibilite uma mobilização política e administrativa capaz de levá-lo adiante (SACHS, 1999). Assim, a descentralização e a participação passam a ser as palavras de ordem, estendem-se como sinônimos de democratização. Para que isso seja efetivado, as reformas institucionais implementadas começam a trabalhar em cima de duas questões: a adequada articulação de todos os espaços de desenvolvimento e a democratização de todos os níveis de governo.

Dessa forma, os movimentos dos cidadãos e associações começam a ter a oportunidade de participação nos níveis locais, regionais e nacional. O Estado passou a utilizar mecanismos que, pretensamente, facilitassem um maior envolvimento da comunidade, através da implementação de conselhos, fóruns, câmaras setoriais etc. A criação desses espaços, que têm o intuito de serem regulados democraticamente para a administração de conflitos, tem como premissa básica que, no momento em que se torne estabelecida a convivência entre interlocutores com diferentes interesses, essa experiência possibilite a construção de uma dimensão propriamente pública. Ou seja, a partir da inserção da sociedade no debate constitutivo de criação e implementação de ações governamentais, pode-se pensar na emergência de uma nova lógica de ação, mais igualitária e que não esteja restrita apenas aos princípios do Estado e do mercado.

Acreditamos que entre o discurso e a prática, muitos pontos ainda precisam ser revistos. Justamente por isso, resolvemos analisar um tipo de ação pública que se diz voltada para a democratização e a descentralização: a I Conferência Municipal de Cultura, realizada na cidade de Olinda, pertencente ao estado de Pernambuco, no ano de 2005. Essa conferência é parte integrante de um projeto, desenvolvido pelo Ministério da Cultura (MinC), que está em consonância com a nova proposta governamental de maior democratização através da inserção da sociedade na elaboração de políticas públicas. De acordo com a proposta do Sistema Nacional de Cultura (SNC), torna-se necessário criar mecanismos que viabilizem uma maior participação da comunidade no tocante à problematização e discussão de questões que envolvem o setor cultural, para a edificação de um novo modelo de política pública cultural no país.

No entanto, o peso das matrizes culturais brasileiras no processo de construção democrática é, de acordo com vários autores, o campo em que as contradições e fragmentações se mostram mais evidentes. O autoritarismo social e as visões hierárquicas excludentes da sociedade e da política são os principais obstáculos para a construção e funcionamento dos espaços públicos. Porém, deve ser ressaltado que a partir do momento em que se coloca em evidência que esses obstáculos existem, somos capazes de buscar combatê-los, e é por meio desse confronto que podem surgir os principais resultados democratizantes. Por isso, percebemos que a inserção da dimensão política na gestão pública é de grande relevância. Compreendemos que todo o processo de gestão participativa envolve a dimensão política; ou seja, para que se torne efetivada a democratização, é necessário que haja uma melhor distribuição do poder.

Portanto, esse artigo pretende contribuir para a área específica dos estudos organizacionais, ao inserir esse conceito nas formas de gestão da administração pública brasileira que têm, ingenuamente, admitido uma separação entre política e administração. Assim, acreditamos que as ações tomadas, levando em consideração a existência dessa dicotomia, são responsáveis pela dissonância percebida entre o discurso e a prática da gestão pública no Brasil. Destarte, ao analisar se as práticas desenvolvidas na I Conferência Municipal Cultura de Olinda podem caracterizar a efetiva participação social difundida na gestão da política de cultura nacional, pretendemos compreender se realmente essa prática está sendo efetuada, visando à participação tanto dos entes federados quanto da sociedade na elaboração de uma política pública nacional. 


\section{Os limites da participação social}

Quando se pretende falar em participação social, não podemos deixar de lado um processo que se traduz na construção da cidadania, que tem como foco a dinâmica da sociedade. Para Telles (2004, p.91), ao tomar a sociedade como foco da discussão, devemos problematizar as "práticas, discursos e valores que afetam o modo como desigualdades e diferenças são figuradas no cenário público, como interesses se expressam e os conflitos se realizam". É com esse intuito que procuramos aqui descrever o processo de participação social promovido pelo Estado brasileiro, utilizando como arcabouço teórico autores que perceberam as incongruências durante o percurso democrático da nossa sociedade. Não temos a intenção de contar a história da democratização pública no Brasil. Esse processo que se pretende instaurar desde o final dos anos 1980 é conhecido nosso. Passamos por várias fases, vários discursos, várias ações que se diziam democráticas, mas e a tão falada democracia, aconteceu? Até agora não!

O que percebemos nos discursos políticos, desde a saída dos militares do poder e o começo do pretenso regime democrático brasileiro, são promessas de uma maior participação da sociedade. O Estado seria o ente capaz de criar condições para que fosse possível gerar descentralização e, conseqüentemente, a tomada de decisões envolveria a sociedade. Vários foram os discursos e ações para que essa democracia fosse implementada no Brasil. No entanto, não se pode deixar de lado o contexto socioeconômico e cultural pelo qual a sociedade passou (e vem passando) desde a década de 1990. A crença na globalização como um processo inevitável e crescente, forçava os países (principalmente, os periféricos como o Brasil) a se submeterem a uma lógica econômica neo-liberal. Sob essa visão, foi implementada uma reforma que estava baseada em uma harmonização entre as economias nacionais, as sociedades e o aparato estatal e uma globalização econômica tida como impossível de ser criticamente combatida. A partir de então, travou-se um reformismo passivo e adaptativo (NOGUEIRA, 2004).

A reforma instaurada deveria, portanto, criar condições que possibilitassem "um crescimento expressivo tanto da governança (a capacidade de implementar políticas públicas) quanto da governabilidade (condições institucionais de legitimação)" (NOGUEIRA, 2004, p.435). Assim, foi concebida uma reforma que trabalhou em favor de uma redução no tamanho do Estado a partir de políticas de privatização, terceirização e parceria entre o público e o privado, que tinham o objetivo de tornar o Estado mais ágil, menor e mais barato.

Por isso, Santos (1997) levanta um questionamento acerca dessa "reemergência da sociedade civil" no discurso político dominante, pois, a seu ver, essa concepção está fundada na idéia clássica de sociedade civil como pluralidade atomística de interesses econômicos privados. Para o autor, o que está verdadeiramente em causa nesse discurso é a substituição do intervencionismo social, interclassista, típico do Estado-providência, por um intervencionismo bicéfalo, mais autoritário com o operariado e a pequena burguesia assalariada e mais diligente no atendimento às exigências macroeconômicas de acúmulo de capital. Apesar do núcleo genuíno que se traduz na reafirmação dos valores do autogoverno, do comunitarismo e da organização autônoma dos interesses, esse núcleo tende a ser omitido ou apenas subscrito dentro do discurso dominante, acabando por corresponder às exigências do novo autoritarismo.

Esse receio com relação à descentralização do Estado e uma maior participação social também está presente no discurso de Demo (1996) quando afirma que esse exercício democrático enfrenta barreiras. Afinal, não se pode deixar de lado os vícios de uma postura clientelista da administração e da própria sociedade que foram construídos ao longo dos anos. Clientelismo esse salientado por Chauí (1994) quando esta considera que fomos fundados sobre uma raiz populista de origem teológica, estabelecida pela teocracia dos dominantes sobre o messianismo dos dominados. Segundo ela, "sendo despótico, teológico e autocrático, o poder populista é uma forma paradigmática de autoritarismo político" (p.21).

Um exemplo de que essas preocupações são importantes e devem ser analisadas no tocante às novas políticas de ação governamental pode ser percebido no estudo de Amantino-de-Andrade e Arenhart (2005). Nesse trabalho, as autoras identificam que, apesar das propostas de conselhos municipais de saúde trazerem um ideal de politização da gestão de saúde e de uma institucionalização das ações de grupos de interesses pelo pacto político, tornando possível exercer o controle social como instrumento democrático, essa socialização do poder 
de renovação estatal a partir da participação não é ainda uma realidade cotidiana nos municípios brasileiros. Em seu estudo, as autoras percebem que os pequenos municípios ainda estão baseados em uma cultura centralizada na ação do Estado, com base em relações de subordinação a esse último, não dando espaço a uma integração político-administrativa na gestão da saúde, pois o que ocorre é simplesmente o cumprimento de uma determinação legal em que os partícipes não ajudaram a tomar decisões e não se sentem responsáveis pelo processo.

Nogueira (2004) aponta que isso ocorre porque, no processo reformista ao longo dos anos 1990, tanto os movimentos sociais quanto a literatura que os acompanhava passaram a mudar de um posicionamento mais combativo e emancipatório, baseado em um conceito mais normativo de sociedade civil, para uma postura pragmática, menos sobrecarregada de expectativas e direcionada para a busca de espaços alternativos em que fosse possível promover um encontro entre Estado e sociedade civil. A incorporação do tema da sociedade civil ao discurso da reforma foi feita, segundo o autor, a partir da redução da visão da sociedade civil ao discurso gerencial. Não se trataria, assim, de uma ação autônoma voltada para a emancipação, mas de uma organização subalternizada, domesticada e concebida de modo técnico. "A sociedade civil seria cooperativa, parceira: não um campo de lutas ou oposições, mas um espaço de colaboração e ação construtiva (voluntariado)" (NOGUEIRA, 2004, p.59).

Ao analisar o discurso político atual, talvez, passemos a nos questionar se essa lógica neoliberal ainda persistirá ou se será alterada, já que o governo federal tem como presidente e parte do seu corpo técnico, membros de um partido político que sempre lutou contra o discurso anterior. Será que é tão fácil mudar as nossas raízes culturais? Quais seriam os limites de uma prática democratizante que agora enfatiza muito mais o protagonismo da sociedade que o do mercado? Para respondermos a essa pergunta, salientamos o argumento de Dagnino (2002) ao levantar a questão de que a natureza dos conflitos está na partilha efetiva do poder. A autora aponta três limitações ao processo participativo que, se solucionadas, podem ocasionar uma verdadeira participação social na gestão pública. A primeira delas está fundamentada nas concepções políticas brasileiras, resistentes à democratização, que são: a dificuldade do Estado em compartilhar o seu poder exclusivo sobre as políticas públicas e, por outro lado, a insistência dos setores da sociedade em participar dessas decisões e concretizar o controle sobre elas. Essa distinção de interesses faz com que as práticas democráticas acabem por se tornar apenas mecanismos de função consultiva ou de legitimação das decisões tomadas nos órgãos públicos. A segunda limitação refere-se às características estruturais do Estado, ainda fundado numa razão tecnoburocrata que dificulta o acesso às informações. Por fim, a exigência de uma maior qualificação técnica e política da sociedade, necessária a uma participação mais igualitária nos espaços públicos. Sem essa qualificação, a sociedade perde poder e, desse modo, o processo democrático torna-se deficiente.

Assim, partindo-se do pressuposto de que o processo democrático brasileiro ainda é muito recente e que, historicamente, estamos fundados numa cultura clientelista, de um Estado autocrático e paternalista, procuramos compreender a forma pela qual essa democracia ocorre. Como pensar em participação social no Brasil, sem levar em consideração os conflitos inerentes a uma sociedade cordial, utilizando o termo de Sérgio Buarque de Holanda, em que a docilidade e a passividade sempre estiveram presentes ante a imposição autoritária dos detentores de poder? Será possível acreditar que, nos últimos anos, fomos capazes de modificar a matriz cultural teológico-política, apontada por Chauí?

\section{Metodologia}

A metodologia adotada em uma pesquisa deverá ter uma função de estruturação e orientação geral da investigação a ser realizada, a fim de apresentar um modelo de trabalho que facilite a coleta e análise de dados (BRYMAN, 1992). Em todo o tipo de pesquisa científica, existe uma estrutura metodológica que irá dar seqüência lógica à ligação entre os dados empíricos e as questões de pesquisa iniciais e, por fim, suas conclusões. Pode-se dizer, portanto, que o desenho da pesquisa é um plano de ação que possibilita ao investigador sair da fase de questionamento inicial para a obtenção de algumas conclusões (respostas) sobre esses questionamentos (YIN, 1994). 
A natureza da pesquisa foi orientada pela perspectiva qualitativa que, conforme Patton (2002), consiste num esforço para entender as situações em suas singularidades como parte de um contexto particular. Esse tipo de investigação, conforme Merriam (1998), ainda se preocupa em compreender o significado das construções das pessoas dentro de um contexto com uma visão holística, abordagem indutiva e investigação naturalística.

Como afirma Merriam, (1998), é por intermédio da observação que a pesquisa é realizada no campo natural de estudo e proporciona um encontro em first hand com o tema escolhido; nesse caso, a participação social. Foi utilizada a observação não participante. Tal método permitiu às pesquisadoras a realização de um estudo exploratório, atuando como espectadoras sem participar da rotina observada, não influenciando o grupo com suas idéias, não partilhando, assim, experiências dentro do grupo pesquisado, demonstrando com isso um consenso com a tipificação de Patton (2002) sobre observação não participante.

Apesar de ter sua ética questionável nesse estudo, o pesquisador preferir se inserir no público em geral. A posição de "completo observador" (MERRIAM, 1998) no método selecionado objetivou atender ao propósito formulado, registrando sistematicamente os fatos, que, segundo Kidder (apud MERRIAM, 1998, p.95), são as atividades da observação em pesquisas.

O contato inicial com o objeto antecedeu o primeiro momento observado, haja vista as pesquisadoras já terem participado de outras reuniões em que o mesmo público estava presente, porém, com outros temas e objetivos. Isso proporcionou um prévio conhecimento de pessoas e organizações relacionadas ao setor cultural, bem como a escolha intencional do objeto.

Considerando a ótica positivista apresentada no texto de Lincoln e Guba (2000), no qual afirmam que, em termos epistemológicos, é assumida uma independência entre o "objeto" investigado e o sujeito investigador, e que um pesquisador é capaz de estudar o objeto sem influenciá-lo ou ser influenciado por ele, as pesquisadoras optaram pela não intromissão em opiniões durante as conversas, haja vista também serem os eventos, plenárias de grande público. Porém, contrariando tal assertiva, perceberam que há a interferência do objeto na relação e opinião do pesquisador, dado que todos sabiam se tratar de pesquisadoras da universidade federal local. Além disso, vale ressaltar que tal método, por envolver um grande conglomerado de pessoas, pode acarretar perda de perspectivas.

Como instrumento principal de coleta de dados foi realizado um diário de campo no qual puderam ser registradas falas e as expressões de sentimentos dos participantes, a composição e a disposição destes em mesas diretoras, principalmente, no tocante à tipificação de poder público ou sociedade civil, e a própria percepção do observador quanto a comportamentos relacionados à participação. Ao mesmo tempo, foram recolhidos e lidos todos os documentos, cartas ao público e panfletos distribuídos em plenárias pelas organizações governamentais e não governamentais presentes, uma vez que, nestas publicações eram expressas opiniões, idéias e valores dos emitentes.

Ainda diante da extensão do evento, foram utilizadas pelas observadoras, além das anotações do diário de campo, gravações de áudio sugerido por Taylor e Bogdan (apud MERRIAM, (1998). Essas ações possibilitam mudar de uma lente de ângulo ampla para uma mais estreita e buscar as palavras-chave nas considerações das pessoas que, segundo Adler e Adler (1994), facilitam a aceitação da pesquisa, dando a esta uma maior confiabilidade. Portanto, pode-se afirmar que nesta pesquisa utilizou-se a técnica de triangulação de coleta de dados que, conforme Triviños (1987), tem o objetivo de descrever, explicar e compreender o foco do estudo em sua máxima amplitude.

\section{O Sistema Nacional de Cultura}

A atual gestão do Ministério da Cultura tem adotado um discurso que assimila o ideal democrático, em consonância com a Constituição Federal de 1988. No entanto, cabe salientar que sua proposta se diferencia das anteriormente adotadas no Brasil, onde o campo da cultura foi deixado de lado no governo Collor, quando o 
Ministério da Cultura foi extinto, e posteriormente foi condicionado pelo discurso neoliberal no governo Fernando Henrique Cardoso. Nesse contexto, passamos de um período de completa anulação do setor cultural para outro em que o setor ficou intimamente relacionado a uma lógica mercantil. As ações voltadas à cultura nessa época foram essencialmente fundadas em organizações e ações culturais que interessavam às empresas patrocinadoras, o que foi institucionalizado, inclusive, a partir de leis de incentivo à cultura (como a Lei Rouanet) que faziam com que as empresas privadas, utilizando isenção fiscal, financiassem os projetos culturais de seu interesse. Isso deu lugar a um caminho que envolvia um domínio do mercado sobre o princípio da comunidade. Era considerado cultura aquilo que gerasse retorno financeiro para as empresas financiadoras, $o$ que valorizou apenas as expressões culturais do tipo espetáculo. A cultura se tornou assim mercadoria.

Com a ascensão de um presidente do Partido dos Trabalhadores, o discurso modificou-se sensivelmente. Os ideais sociais que movem o partido e a maioria de seus integrantes estão fortemente presentes nas ações do Ministério da Cultura atual. A participação social tem sido insistentemente enfatizada pelo ministro Gilberto Gil e diversos programas estão sendo desenvolvidos com o intuito aparente de criar mecanismos geradores de uma gestão compartilhada e transformadora. Nas palavras do ministro:

[...] inúmeras iniciativas culturais resultam do esforço, da vocação e da mobilização de pessoas, grupos e organizações. Essas ações têm como foco a cultura como instrumento de construção de identidade e cidadania, meio pedagógico ou como um processo que - vivenciado pela comunidade fortalece o sentido de pertencimento social, contribuindo para a ampliação das possibilidades de vida e de escolhas. (BRASIL, 2005)

Assim, podemos perceber no MinC uma série de ações pautadas por um discurso segundo o qual a cultura é um importante (se não o mais importante) elemento gerador de cidadania, e que, para que isso seja efetivado, a relação entre Estado e sociedade deve ser alterada através de uma maior participação social. A concepção de seus projetos pretende salientar que as ações culturais devem ser deslocadas do centro para o local. Isto é, cabe à sociedade, em conjunto com seus municípios e estados, definir o que é melhor para cada localidade e, portanto, o papel do governo federal deve ser o de criar mecanismos para que isso ocorra.

Então, a partir de 2004 foram realizadas reuniões com secretarias municipais e estaduais de cultura e com alguns setores da sociedade civil. Tudo isso foi feito com o intuito de institucionalizar o que ficou denominado de Sistema Nacional de Cultura (SNC), que tem como objetivo ser um "sistema de articulação, gestão, informação e promoção de políticas públicas de cultura, pactuando os entes federados, com a participação social" (BRASIL, 2005).

Para a constituição de um sistema de cultura efetivamente nacional, torna-se imprescindível a consolidação de sistemas próprios dos entes, ou seja, de sistemas federal, estaduais e municipais ou intermunicipais de Cultura. Municípios vizinhos podem optar pela instituição de sistemas/consórcios em conjunto, estruturarem seus sistemas culturais pelas respectivas microrregiões, de forma a garantir as condições adequadas de planejamento, gestão e agrupamento das ações e instalações culturais.

A viabilização dos sistemas de cultura depende principalmente da participação da sociedade civil para a definição de prioridades e o controle e acompanhamento das metas programadas. Mais do que isso, por corresponderem pelo maior volume das ações e do calendário cultural do país, se deve destinar à sociedade civil parte substantiva dos programas culturais fomentados pelo Estado. A sociedade civil cumpre, portanto, papel decisivo na construção dos sistemas culturais públicos e do Estado democrático. (BRASIL 2005)

Para que o SNC fosse então implementado, o Ministério da Cultura elaborou um passo a passo que está estruturado da seguinte forma: (1) realização, nas cinco regiões do país, de seminários setoriais de cultura que contaram com a participação de representantes de instituições, movimentos sociais e colegiados dos diferentes segmentos artísticos. Nesses seminários foram definidas as prioridades relativas a cinco eixos temáticos propostos pelo MinC, que foram os norteadores dos debates posteriormente realizados; (2) conferências 
municipais com os municípios que assinaram um protocolo de intenções com a União. Essas conferências foram abertas à participação da sociedade, em conjunto com as respectivas secretarias de Cultura em que os representantes (delegados) da sociedade civil e do poder público apontaram propostas para as (3) conferências estaduais, que foram o próximo passo do processo. Essas conferências tiveram como objetivo, além de discutir as propostas provenientes dos municípios, levantar subsídios para o órgão coordenador (secretaria ou fundação) da política cultural de cada estado; e, por fim, (4) a plenária nacional, realizada em dezembro de 2005 em Brasília, utilizou-se das propostas provenientes dos estados para subsidiar o MinC e o Conselho Nacional de Política Cultural (CNPC), na (5) elaboração de um Plano Nacional de Cultura (PNC) - o que ainda não ocorreu.

No entanto, todo esse percurso, descrito nos documentos e discursos do Ministério da Cultura, parece-nos tão consensual e harmônico que chega a causar estranheza. Afinal, os interesses do poder público (em seus níveis municipal estadual e federal) são os mesmos da sociedade? Se participação social envolve partilha de poder, deve-se reduzir o poder de um em benefício do outro, ou seja, transfere-se parte do poder do Estado para a sociedade. Mas essa transferência não acontece de forma harmoniosa, é uma disputa, um jogo de ganha/perde. A forma como a proposta é apresentada pelo MinC parece querer demonstrar que o Estado está disposto a abrir mão do seu poder em benefício da sociedade, em prol do "bem comum". Será que isso é tão fácil como está descrito? Com esse questionamento em mente, buscamos compreender a lógica desse processo, antes mesmo dele ser encerrado a partir da análise de um caso específico. A descrição a seguir trata de como as conferências municipal de Olinda e estadual de Pernambuco demonstram força (ou não) para promover uma efetiva participação social na implementação de políticas públicas culturais no Brasil.

\section{Seminário preparatório e Conferência Municipal de Olinda}

À luz do Sistema Nacional de Cultura (SNC), a pesquisa contextualiza três momentos diferentes: seminário preparatório; a I Conferência Municipal de Políticas Culturais de Olinda e a Conferência Estadual de Pernambuco. Essas observações foram realizadas no intuito de avaliar a evolução do processo de articulação entre a sociedade e o poder público na elaboração de uma gestão participativa no setor cultural do município de Olinda.

O seminário preparatório foi realizado a partir da necessidade de iniciar a construção de uma identidade cultural do município, no que tange à participação em todo o processo. Elaborado e desenvolvido pela Secretaria do Patrimônio, Ciência, Cultura e Turismo do município de Olinda (Sepacctur), teve como tema o Sistema Nacional de Cultura (SNC), objetivo maior de todas as articulações entre o poder público e a sociedade civil, que foi consolidado na Conferência Nacional de Cultura em dezembro de 2005.

O seminário foi estruturado em blocos, nos quais foram abordados, de maneira explicativa, os seguintes temas: a proposta do SNC, o processo de construção do Plano Municipal de Cultura - participação e controle social, a Conferência Municipal, o Conselho Municipal de Cultura e o Fundo Municipal de Cultura.

Foram iniciadas discussões quando do franqueamento da palavra aos representantes preestabelecidos. O do poder público fez uso para lançar alguns questionamentos de reflexão à plenária, sobre política de gestão, democracia e educação. Também foi exposto, através de um representante da sociedade civil, o pensamento do movimento cultural olindense sobre o processo e em relação à Secretaria de Cultura. O mesmo elencou conceitos como o dos direitos sociais, de participação e de cidadania, além de expor idéias, diretrizes e opiniões de uma organização informal, o Fórum dos Artistas e Produtores Culturais de Olinda, acerca dos conselhos de cultura.

Cabe salientar que esse representante da sociedade civil foi convidado pela Secretaria de Cultura para falar. Não foi uma fala espontânea. Outro ponto que se deve levar em consideração é que, posteriormente, na conferência municipal, o mesmo teve um papel determinante. Ao tentar compreender o porquê desse fato, não se pode deixar de lado que esse representante, o qual chamaremos de João, é produtor cultural da cidade, e 
articulou, com outros artistas e produtores, um fórum de debate especialmente para discutir suas ações nas conferências municipal e estadual.

Na plenária foram externadas as mais variadas opiniões e críticas sobre movimentos culturais, abertura de mercado para as organizações culturais como meio de manutenção e sobrevivência da cultura. Os eixos temáticos foram:

- gestão pública da cultura;

- economia da cultura;

- patrimônio cultural;

- cultura é cidadania e democracia (cultura é direito e cidadania);

- comunicação é cultura.

Durante todo o evento foi observada a articulação e organização dos partícipes oradores, representantes da sociedade civil (João e outro membro do fórum, a quem chamaremos de José), distribuindo documentos impressos contendo a ideologia do discurso exposto(tal material foi distribuído em conjunto com o material de apoio do evento nas entradas de acesso à plenária).

Na seqüência de eventos, foi realizada a I Conferência Municipal de Cultura em Olinda, que, segundo a Portaria $\mathrm{n}^{\mathrm{o}}$ 180/2005 do MinC, só poderia acontecer após a assinatura do protocolo de intenções com a União; ou seja, uma vez mais se percebe a presença de uma dominação racional-legal do Estado sobre o processo.

Ainda de acordo com a portaria,

As conferências municipais ou intermunicipais têm o objetivo de levantar subsídios para os respectivos planos municipais/intermunicipais de cultura. E têm também a responsabilidade de apontar propostas para as respectivas conferências estaduais, para a Plenária Nacional e, no caso da Nacional, para o Conselho Nacional de Política Cultural, que estabelecerá as diretrizes gerais do Plano Nacional de Cultura. Além das questões locais, as conferências municipais tratam dos cinco eixos temáticos eleitos como centrais na $1^{\underline{a}}$ CNC. Constituem-se, portanto, como etapas preparatórias da conferência nacional. Abertas à participação de cidadãos em geral, as conferências municipais e intermunicipais elegem os delegados para as conferências estaduais.(BRASIL,2005)

Um ponto observado no evento foi a articulação realizada por uma entidade civil, o Fórum dos Artistas e Produtores Culturais de Olinda. No momento em que a plenária foi distribuída aleatoriamente para discussão dos eixos temáticos, propostos pelo Ministério da Cultura, cada integrante do fórum ficou em uma sala temática diferente para que o fórum participasse e acompanhasse todas as decisões. Uma vez previamente elaboradas, suas propostas, foram distribuídas a todos. Articulação essa que não se resumiu à presença nas equipes de trabalho, haja vista que no último dia de conferência foi efetuada por integrantes dessa entidade uma verdadeira campanha para a elaboração de uma chapa única, com candidatos a delegados a serem eleitos como representantes de Olinda na Conferência Estadual de Cultura de Pernambuco. Salientando que todos eram participantes do fórum e foram aclamados pela plenária.

\section{As conferências estadual e nacional}

A I Conferência Estadual de Cultura de Pernambuco foi realizada em novembro de 2005, convocada pela Portaria n⿳0 6.064/2005 com o tema "Estado e sociedade construindo as políticas públicas de cultura".

Estavam envolvidos 411 municípios do estado, perfazendo um total de 410 participantes, dos quais 338 eram delegados representantes dos movimentos artísticos, culturais e sociais tipificados como sociedade civil, 50 delegados representantes do poder público e 22 convidados de instituições culturais com sede no estado de Pernambuco. 
No ato do credenciamento foram distribuídas cópias do regimento interno e das sistematizações de propostas de acordo com os eixos temáticos definidos anteriormente pelo Ministério da Cultura. Vale salientar que a Conferência foi fechada ao público não credenciado anteriormente, havendo mesmo assim, tentativas de participação, algumas com fraudes de crachá, na intenção de advogar em causa própria nas votações e eleições.

O evento estava programado da seguinte forma:

- Solenidade de abertura;

- análise e aprovação do regimento interno;

- seis plenárias temáticas divididas pelos eixos de trabalho definidos pelo MinC;

- uma plenária final para aprovação de propostas e moções e para escolha dos delegados que participariam da I Conferência Nacional de Cultura; e

- encerramento das atividades com apresentação de grupos culturais.

Como o evento estava relacionado a todo o Estado e o foco da pesquisa é o município de Olinda, escolhemos a plenária de encerramento, com o intuito de avaliar o resultado das articulações anteriores e direcionadas a tal ocorrência. Foram registradas no diário de campo apenas as observações referentes às conversas paralelas ocorridas do lado de fora da plenária entre alguns atores de Olinda. Um fato que chamou a atenção foi o de que a organização e o funcionamento do evento foram, em todas as situações, geridos pelo poder público ou por alguém designado por este.

Foi gerado um conflito no início do evento, durante a aprovação do regimento interno, concernente à quantidade/proporcionalidade de delegados a serem eleitos e enviados à conferência nacional, por regiões do estado, mais precisamente entre a região metropolitana e o interior. Após muitas discussões e controvérsias entres os pólos, foi refeito tal proporcionalidade, mas o mal-estar e a desarticulação da sociedade civil perduraram até os momentos finais, mostrando com isso uma falta de estrutura quanto à organização do evento.

Atentamos também para as articulações e os acordos políticos feitos de última hora para eleição dos delegados do poder público, em que a sociedade teve participação influente nas eleições. Foram muitas as divergências entre o poder público e a sociedade nas últimas e mais importantes votações. Mesmo quando estas foram encerradas, era perceptível a continuação das discussões paralelas. Foi percebida também a existência de uma centralização de decisões e hierarquia muito concentrada nas mãos do poder público, bem como nos outros eventos já citados, a indiferença e o descaso de alguns componentes da mesa. Vale ressaltar que sua maioria era de representantes do poder público, quando do uso da palavra pela sociedade civil. Observamos também nas conversas paralelas do lado de fora da plenária a insatisfação com o evento e com os rumos que foram tomados na formação da delegação para à conferência nacional.

\section{Os resultados até o momento: do global para o local?}

Podemos perceber que diversos autores apresentam seus pontos de vista com relação a esse processo de mudança social, e parece haver um consenso de que o Estado é um importante agente na condução de um mundo melhor e mais justo. No entanto, esse é um trabalho que não pode ser deixado como exclusivo do Estado. Na verdade, ele

precisa ser inventado e de novo, reestatizado, fundado novamente. Se um Estado é indispensável, não é porque a sociedade, a democracia ou a sociedade civil precisem de um 'tutor', mas o contrário: é porque essa é uma das condições para que elas sejam mais autônomas e potentes (NOGUEIRA, 2003, p.67).

Apesar do discurso de uma reforma fundada na cidadania e na participação social, muitas propostas participativas, segundo Demo (1996), acabam camuflando novas e sutis repressões. Afinal, se participação estabelece uma disputa com o poder, criando outra forma de poder, o poder de controle social pela própria 
sociedade, o que vemos hoje nos processos de gestão participativa não passa, meramente, de uma forma de "manter tudo igual", de deixar no poder quem sempre esteve.

Conforme foi apresentado neste artigo, apesar do crescente discurso acerca da participação comunitária, no Brasil, isso ainda não foi plenamente efetivado. O que vem ocorrendo é que a sociedade se vê, de certa forma, obrigada a participar de conselhos ou fóruns de participação que não foram criados pela própria comunidade, tornando-se assim apenas um agente que aceita as determinações impostas pelo Estado. Essas ações, na maioria das vezes, têm tirado o cidadão do processo de planejamento participativo, o que lhe torna um agente alheio a todo o processo e acaba por burocratizar as ações ditas comunitárias. As pessoas não se envolvem, não discutem e o Estado continua a impor suas regras, só que dessa vez com uma força maior, já que tem a legitimidade da comunidade.

Portanto, é possível intuir que o Estado, ao "delegar" e/ou "descentralizar" as questões de natureza social para outros agentes, pode transformar entes públicos em privados, de ação emancipatória em compensatória (TENÓRIO, 2002). Assim, artistas, produtores e organizações culturais seriam levados a atuar em busca da eficiência e do consumo, deixando de lado a livre expressão de sua arte baseada em valores democráticos e de solidariedade humana, passando a se preocuparem mais com questões políticas e/ou econômicas. Isso, no entanto, não é salutar para um pretenso desenvolvimento societal, pois apesar de ser inegável a importância do campo cultural, não se pode perder de vista que o seu contexto é mais amplo, pois a cultura é um fator primordial ao desenvolvimento social, ao pleno exercício da democracia e da cidadania (BRANT, 2003).

Apesar de possuir um discurso diferente dos demais, de parecer não destacar o neoliberalismo econômico e efetivar a ação de uma sociedade, ainda há que se analisar o processo democrático brasileiro de modo cauteloso. Não é fácil dividir poderes, como foi percebido nesse caso. Apesar do objetivo ser aumentar a participação, muitas das ações foram tomadas de cima para baixo. No entanto, não podemos deixar de perceber que essa é uma prática diferenciada justamente por podermos visualizar a satisfação da sociedade civil de Olinda com o processo da conferência municipal realizado no município. Apesar disso, cabe salientar o descontentamento dos mesmos quanto à Conferência Estadual. Será que a percepção de que a prefeitura de Olinda foi mais igualitária que o governo do estado está relacionado com os partidos políticos de seus representantes (o primeiro é aliado do governo federal e o último, contra)?

Outro ponto a se destacar, com relação à participação da sociedade civil, é que podemos perceber que em Olinda, esta estava bem articulada. Talvez por ser uma cidade com grande efervescência cultural, a sociedade civil se estruturou a partir do momento que soube da proposta do MinC com relação ao SNC, o que ficou muito claro nas conferências. Os participantes desse fórum foram responsáveis por um fortalecimento das decisões da sociedade civil na elaboração da proposta.

No entanto, não conseguimos ainda (e achamos que nem devemos) observar esse discurso de forma acrítica. A raiz cultural clientelista que foi instaurada no Brasil desde a sua colonização, e reafirmada ao longo dos anos, demonstra uma evidente separação entre administração e política e, como dito anteriormente, parece impossível querer tratar a democratização sem perceber o jogo político que existe nesse processo. O próprio discurso anteriormente apontado parece querer evidenciar uma relação não conflituosa entre Estado e sociedade, como se os interesses de ambos fossem os mesmos. Não é! O conflito existe e é a partir dele, em nossa opinião, que a democracia pode ser efetivada. Afinal, se os interesses do Estado atingem plenamente os anseios da comunidade, qual seria o sentido de tornar o cidadão partícipe no processo de criação e implementação de políticas públicas? Se assim o fosse, o exercício da cidadania seria plenamente realizado e concluído no momento das eleições. 


\section{Referências}

ADLER, P. A.; ADLER, P. Observational techniques. In: DENZIN, N. K.; LINCOLN, Y. S. (Ed.). Handbook of qualitative research. Thousand Oaks: Sage, 1994. p.377-392.

AMANTINO-DE-ANDRADE, J.; ARENHART, A. J. Participación social en el Sistema Único de Salud: una utopía por cumplirse en municipios de pequeño porte del Valle del Taquari. In: MISOCZKY, M. C.; BORDIN, R. (Org.). Géstion local de salud, prácticas y reflexiones. Porto Alegre: DaCasa, 2005, p.37-56.

BRANT, L. Politicas culturais. São Paulo: Manole, 2003. v.1

BRASIL. Ministério da Cultura (MinC). Disponivel em: <http://www.premioculturaviva.org.br/premio_textodoministrodacultura.php>. Acesso em: 11 dez. 2005.

<http://www.cultura.gov.br/foruns_de_cultura/conferencia_nacional_de_cultura/index.html> Acesso em: 10 dez. 2005.

BRYMAN, A. Research methods and organization studies. London: Routledge, 1992.

CHAUÍ, M. S. Raízes teológicas do populismo no Brasil: teocracia dos dominantes, messianismo dos dominados. In: DAGNINO, E. (Org.). Anos 90, política e sociedade no Brasil. São Paulo: Brasiliense. 1994, p.19-30.

DAGNINO, E. Sociedade civil e espaços públicos no Brasil. São Paulo: Paz e Terra, 2002.

DEMO, P. Participação é conquista. In: Politica social e participação. 3.ed. São Paulo: Cortez, 1996

LINCOLN, Y. S.; GUBA, E. G. Paradigmatic controversies, contradictions and emerging confluences. In: DENZIN, N. K.; LINCOLN, Y. S. (Ed.). Handbook of qualitative research. 2nd ed. Thousand Oaks: Sage, 2000. p.163- 188.

MERRIAM, S. B. Qualitative research and case study applications in education. 2nd ed. San Francisco: Jossey-Bass, 1998.

NOGUEIRA, M. A. As três idéias de sociedade civil, o Estado e a politização. In: COUTINHO, C. N.; TEIXEIRA, A. P. (Org.). Ler Gramsci, entender a realidade. Rio de Janeiro: Civilização Brasileira, 2003.

Um Estado para a sociedade civil: temas éticos e políticos da gestão democrática. São Paulo: Cortez, 2004.

PATTON, M. Q. Fieldwork strategies and observation methods. In: Qualitative research \& evaluation methods. 3 rd. Thousand Oaks: Sage, 2002. p.259-332.

SACHS, I. 0 estado e os parceiros sociais: negociando um pacto de desenvolvimento. In: BRESSER PEREIRA, J. W.; SOLA, L. (Org.). Sociedades e estado em transformação. São Paulo: Unesp, 1999.

SANTOS, B. S. Pela mão de Alice: o social e o político na pós-modernidade. 4.ed. São Paulo: Cortez, 1997.

TELLES, V. S. Sociedade civil e a construção de espaços públicos. In: DAGNINO, E. (Org.). Anos 90, política e sociedade no Brasil. São Paulo: Brasiliense, 2004.

TENÓRIO, F. G. Tem razão a administração? Ensaios de teoria organizacional e gestão social. ljuí: Nobel, 2002.

TRIVIÑOS, Augusto N. S.. Introdução à Pesquisa em Ciências Sociais. São Paulo: Atlas, 1987.

YIN, R. K. Estudo de caso: planejamento e métodos. Porto Alegre: Bookman, 1994. 